\title{
Applications Strategy Language Lab in Foreign Language Teaching Reform
}

\author{
jun Zhang ${ }^{1, \text { a }}$ \\ ${ }^{1}$ BOHAl University, China \\ azhangjungina@sina.com
}

Keywords: Language laboratories, Foreign language teaching, Reform, Application strategy.

\begin{abstract}
Students nowadays more and more attention of foreign languages training colleges and universities, has been through the whole process of modern foreign language teaching. Using the language laboratory can effectively improve the quality of foreign language teaching, it has become the consensus of Western education sector. In this paper, the characteristics of digital network language lab and use discussions, study in foreign language teaching, the role and application of digital language laboratory network should pay attention to the issue.
\end{abstract}

\section{Introduction}

Theoretical Foundation Digital Language Laboratory combines "learning and teaching" Theory of Constructivism and Ausubel's "teaching and learning" theory. Constructivism emphasizes student-centered, its learning theory and learning environments require students to be the subject of information processing and knowledge of active construction of meaning, just to play against the indoctrination target students passive recipients of external stimuli and knowledge. For teachers, teaching theory of constructivism noted that the main role of teachers should help students actively construct, facilitator, and should not be imparting knowledge, instill person. Teachers should constantly with new teaching ideas to arm themselves, in the teaching process constantly updated teaching mode, new teaching methods and new teaching design, which help students to assume and facilitator[1]. Ausubel noted that achieving meaningful learning can have two different approaches and methods: receptive learning and discovery learning. Reception learning, students assume the role of main passive recipients of knowledge, mainly relies on the role played by teachers. Teachers through the "pass - to accept the" teaching method to achieve the purpose of teaching; and discovery learning, students play is the active construction of knowledge. Students through "self-discovery" of learning play the main role of cognition[1]. Thus completing is the process of constructing knowledge. Ausubel proposed "advance organizers" of teaching strategies according to this theory. He also believes that the impact of emotional factors on learning motivation to work through.

\section{Virtual reality technology}

Virtual reality technology, the image has been called the "spiritual environment", is the use of three-dimensional computer technology to simulate the real environment generated in the space, and by allowing the user a variety of sensing devices "immersion" into the virtual environment, to achieve the user and environmental technology directly interact. As a rising star, VR gradually is superiority and scalability. The virtual reality technology is introduced into the sports field utilization, so that exercise training reflects a more scientific, systematic, innovation. BurdeaG and PhilippeCoiffet made the famous "3I" Theory in 1993 annual meeting of the world's electronics, that VR technology has three salient features: immersion (Immersion), interactivity (Interactivity) and imagination [2]. And these three features with many aspects of sports training and competitions at both fit.

According to "learning and teaching" Theory of Constructivism and Ausubel's "teaching and learning" theory, combined with the characteristics of digital language lab, we recognize that digital language laboratory can greatly stimulate learning motivation, fully mobilize a variety of senses thereby to achieve a multi-modal knowledge construction process. Meanwhile, the digital language 
laboratory can achieve autonomous learning, exploratory learning, collaborative learning, to provide strong support and guarantee for the continuous development of foreign language teaching.

\section{Digital language lab features and functionality}

With the continuous development of information technology, digital language laboratory has been developed to the third generation. Compared with the previous two generations of digital language laboratory, the third generation of digital language laboratory has the following functions and features:

Multi-channel broadcasting function. That can be a teacher, the students are divided into several groups, each group to broadcast different learning content and information. Through multi-channel broadcasting function, we can achieve small class teaching, group teaching. Teachers can specify any digital audio data or image data to a bit, a group, or all students, highly targeted. At the same time, teachers depending on their level of knowledge, learning characteristics, learning limited scope, broadcast the most appropriate learning resources, so as to achieve individualized goals [3].

Rich Western repository.The third generation of digital language lab not only in itself can store large amounts of teaching resources, along with the network technology used in language lab, we can also make full use of learning resources on the network, so that the database updated continuously enriched. All kinds of foreign language teaching resources, teachers may need to store the text data according to the teaching, audio data, video data and so on. Such as various types of the original novel, the movie soundtrack, foreign news programs, broadcast-type programs. Greatly enriched the learning library, both to meet the needs of students, but also for teachers to provide more information. The third generation of digital language lab full use of computer multimedia and network technology, the integration of more high-quality rich multimedia foreign language learning resource, with a more complete teaching learning and assessment functions, enabling multi-modal vocational foreign language teaching, but also promoted the students' self-learning.

Diversification of digital recording. This function can be ready to record conversations within the next classroom. Thus students in verbal learning, you can always record your own pronunciation, either hear their pronunciation circumstances, there can hear the pronunciation of other students, students can use the recording feature reading contrast exercise by playing back to find out insufficient, targeted to be modified to correct pronunciation, so that their more standard pronunciation. In addition, you can also perform oral examination in the digital language lab. While oral expression of students, recorded sound can be synchronized, and production files in MP3 format. Examination process, teachers can put the contents of students' oral exam expressed recorded by the device, and wait until all the students finished, the teacher can playback recorded audio data examination, also can be done on the computer scoring [4].

\section{Significance and role of digital language laboratory construction}

The third generation of digital language lab for foreign language teaching tailored to a lot of features, along with the reform of foreign language teaching in our country and continues to develop. Therefore, the current language laboratories to meet the requirements of vocational foreign language teaching, and provide a strong technical support for the development of vocational foreign language teaching, a strong impetus to the reform and innovation in Vocational Foreign Language Teaching.

Personalized teaching environment.Foreign emphasize practical, so the teacher should use the rich resources and means of digital language lab features for different students, to provide students with a personalized learning environment. In comparison with the more traditional foreign language teaching examination for the purpose of memory and more attention to explain grammar vocabulary, it can ignore the student's own characteristics and professional needs[3]. On the digital language of classroom teachers can use the experimental group functions to achieve group teaching, so that students find their own team, truly personalized teaching environment. Next, the author from teaching content, teaching process and teaching methods described three multimedia classrooms is how to give their children a personalized learning environment. 
Table 1. Personalized teaching enviroment

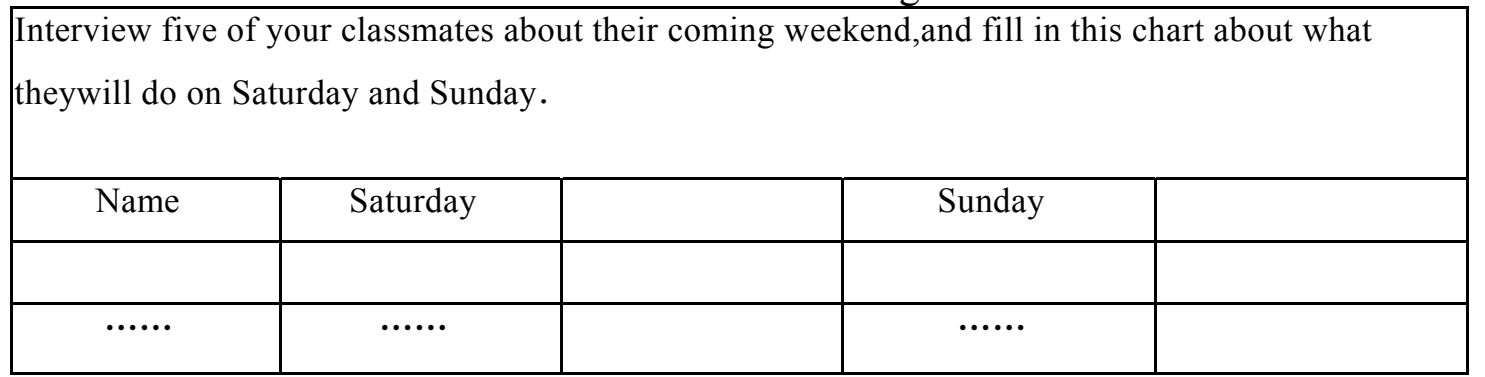

a. Problems of teaching content. Teachers should first clear the purpose of teaching a foreign language, a full understanding of teaching content[4]. To develop practical vocational talents as a starting point, set meaningful teaching problems according to specific teaching content. Such students can clear learning task, a reasonable allocation of the various modes of use, targeted at the digital language lab to carry out multi-modal learning. At the same time, teachers can also be problems, and the student solutions to the web, to improve students' self learning reference.

b. Exploration of the teaching process. When the teachers will be problems and solutions spread to the Internet, students can take the initiative to obtain relevant information and other network information[4]. This is the basis of inquiry learning. After obtaining the basic issues and information, students in the classroom can be discussed and collective self inquiry form for topics of interest to carry out collective discussions. Teachers should look on an equal per student. This way changed the inheritance pattern of the old teaching mode Instead inquiry learning.

c. Individualized teaching methods. Digital Language Lab has a packet function. It can be divided into different study groups of students, teachers in teaching personalized packet of the characteristics of the different groups[4]. This personalized teaching can be reflected in personalized teaching content, personalized teaching mode, and personalized learning mode. For example, higher levels of foreign language teachers can let students learn the content of their choice according to their interest in learning and a good grasp of their own learning progress. As for foreign language children with learning difficulties, you can specify the group he chose to study the basics. Thus in the group where students can help each other, it will not cause too much psychological pressure. Digital language lab teaching grouping feature that allows different levels of interest in different learning children to find the most suitable for their own learning mode and learning companion.

Provide exploratory, collaborative learning environment. Multimodal foreign language teaching will be based on digital language laboratory student position on the subject. Students learn in-depth knowledge and the best way to fully grasp the knowledge is exploratory learning. In collaborative learning, students are not passive recipients, but active participants. Student aid of advanced digital language lab equipment, expand the group discussion, role playing and other teaching activities, students collaborate in this process, to play their respective expertise, in a cooperative way to complete a learning task. In collaborative learning, each person is a separate individual has autonomy, is in development, full of potential, the integrity of the person. It is an active participant in the learning process. Students can express their views, to express their views' [5].

Foreign Language Teaching Based on digital language lab. Teaching teachers to guide students to use a variety of teaching and learning conditions in education process learning materials, generally include preparation, classes, assignments, correcting homework, teaching evaluation and other sectors. Different environments and different classes of teaching methods can lead to differences in teaching, thus changing the behavior of teachers and students' learning behavior. Such as non-multimedia classrooms and digital language lab will provide a different learning environment, teachers would take different teaching mode according to the characteristics of each classroom, causing differences in student learning methods and effects.

\section{Implementation of Digital Language Laboratory multi-modal teaching}

The third generation of Digital Language Laboratory in teaching materials, online resources, hard-disk recording, data storage, several aspects of paperless test, self-learning foreign language 
teaching provides professional language learning environment, the formation of a new teaching resources and the environment. It rich audio and video teaching resources greatly attracted the attention of students to fully mobilize the students a variety of senses of sight, hearing, touch, etc., so that students into the full range of foreign language learning among the more vocational foreign language modal teaching provides an effective platform. Digital Language Laboratory implementation multimodal teaching is mainly reflected in the following aspects.

\begin{tabular}{|c|c|c|c|c|}
\hline $\begin{array}{l}\text { Non-communica- } \\
\text { tive learning }\end{array}$ & $\begin{array}{l}\text { Pre-communicative } \\
\text { language practice }\end{array}$ & $\begin{array}{c}\text { Communicative } \\
\text { language practice }\end{array}$ & $\begin{array}{c}\text { Structured } \\
\text { communication }\end{array}$ & $\begin{array}{c}\text { Authentic } \\
\text { communication }\end{array}$ \\
\hline Focus on form & & 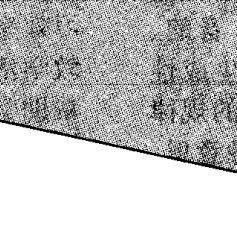 & & (i) \\
\hline
\end{tabular}

Fig.1 Digital Language Laboratory implementation multimodal teaching

Provide multi-modal teaching resources. A variety of multi-modal sensory stimulation of foreign language teaching mobilize sufficient visual, auditory, tactile and other means of digital language lab huge learning resources, set sound, graphics, text and other information in one, to provide students with an interactive language environment, so that students have the knowledge system has been activated. At the same time, teachers can and with the multi-modal interaction effect, guide students through understanding, discussion, research and language-related cultural phenomenon from a multidimensional perspective of understanding the language, the language analysis. Digital language laboratory in cooperation with the multi-modal teaching model both can change the traditional textbook as the main resource to the board as the main teaching means teaching. Rich teaching resources to make up for the shortage of book knowledge, multi-modal teaching mode can build a variety of information resources. Based on the characteristics of the largest network of digital language lab is the vast network of teaching resources. It reflects the diversity and multi-modal teaching resources [6].

Multichannel teaching information transfer. Language learning is a learned process, the degree of mobilization of students for each of the senses directly affect the SLA effect. Research shows that learners feel, learning and memory will affect the learners learning. There are many learners receive information channel, such as from a sense of smell, sight, taste, touch, hearing and so on. The use of digital language laboratory, multi-modal technology can build a variety of sensing modes, such as visual and auditory, etc., at the same time the information content of the tutorial visualize, concrete, diversification, the ability to make and restore language symbol behind reality (virtual reality) capabilities and the ability to render symbol extension language meaning and connotation meaning, which is beneficial to demonstrate the advantages of resources from all angles of the multi-channel nature.Multi-modal Western courseware may contain a lot of text, images, sound and animation. It reflects the diversity of the information carrier. Diversity, integration, interaction, distribution and digital features. It can deliver huge information resources, and can be expanded from multiple dimensions. The advantages of multi-modal Western courseware that he can be integrated according to a variety of different classes love teaching objectives, while it is very flexible manner, encourage students to various senses are mobilized, teaching methods becoming more flexible, thereby mobilizing the students various senses, improve the students' study enthusiasm. When digital language lab practical PPT courseware, multi-modal nature generally reflected in three aspects: visual modality, visual mode and video mode. PPT on the one hand to reflect the content of textbooks, then take advantage of the visual modality for students to demonstrate knowledge and other background information. When explaining the text, it can help students to extract meaningful information from the virtual scene, exercise the logical thinking ability of students. On the other hand, when the PPT or video resources to show the hearing on the use of audio-visual combination of modes. Namely through the audio data and video information auditory and visual mobilize students to 
improve their ability to identify, to improve learning efficiency and students' communicative ability. Third, the video mode is used frequently in animation, news, movies and other video, this mode can be linear or three-dimensional brain training brain thinking, to help students understand the concept of discourse deeper system. The use of video modes can stimulate thinking three-dimensional, linear thinking brain, etc., to encourage students to discourse generating system and a deep understanding of concepts [7].

In summary, the important role of virtual reality technology in sport, as well as their application in a variety of sports, so sports field there is a major change, which has important implications for the future of sports and sports unfolds, at the same time, is further evidence that the use of virtual reality technology in sport is essential.

\section{Conclusion}

Digital language lab as a new language teaching system, not only can make up the traditional teaching of modern teaching methods to promote on the basis of inadequate, and in optimizing the premise of college teachers and the learning environment to improve teaching quality and efficiency of learning. Against the backdrop of the digital era of rapid development, we want to disseminate information in various ways with the media has an updated understanding and awareness, so that the digital language laboratory to play a greater role and value in foreign language teaching.

\section{References}

[1] X. Wang, On the Digital Network Language Lab in Foreign Language Teaching, Education and occupation, 2006, pp.32-36.

[2] H.B. Wang, Foreign Language Teaching and Network Digital Language Laboratory, China Modern Education Equipment, 2006, pp.8-13.

[3] X.P. Zhou, China Education Technology (AVE) association, Digital language learning system specification. 2012,pp.214-221.

[4] A.M. Pan, Computer Networks (fourth edition), Beijing: Tsinghua University Press, 2005.

[5] H.T. Wu, Digital Language Lab of Foreign Language Teaching Service practice, Chinese technical equipment, 2007,pp.25-31.

[6] Y.P. Yao,On the language laboratory specific applications in foreign language teaching reform, disciplines. 2013,pp.53-56.

[7] R.R. Liu, Modern Educational Technology - Trend Information Education, Xi'an: Shaanxi People's Publishing House, 2006,pp.312-318. 